\title{
Myocardial ischemia assessment in chronic kidney disease: challenges and pitfalls
}

\author{
Susie F. C. Parnham ${ }^{1,2}$, Jonathan M. Gleadle ${ }^{2,3}$, Carmine G. De Pasquale ${ }^{1,2}$ and Joseph B. Selvanayagam ${ }^{1,2}$ * \\ ${ }^{1}$ Department of Cardiovascular Medicine, Flinders Medical Centre, Bedford Park, SA, Australia \\ 2 School of Medicine, Flinders University, Bedford Park, SA, Australia \\ ${ }^{3}$ Department of Renal Medicine, School of Medicine, Flinders University, Bedford Park, SA, Australia
}

Edited by:

Nicola Mumoli, ASL 6 Livorno, Italy

Reviewed by:

Probal Roy, Concord Hospital,

Australia

Rajesh Puranik, Royal Prince Alfred

Hospital, Australia

*Correspondence:

Joseph B. Selvanayagam,

Department of Cardiovascular

Medicine, Flinders Medical Centre,

Bedford Park, SA 5042, Australia

e-mail: joseph.selva@health.sa.gov.au
Coronary artery disease is the leading cause of mortality and morbidity in the chronic kidney disease (CKD) population and often presents with atypical symptoms. Current diagnostic investigations of myocardial ischemia in CKD lack sensitivity and specificity or may have adverse effects. We present a case vignette and explore the challenges of diagnostic myocardial stress investigation in patients with CKD.

Keywords: chronic kidney disease, myocardial ischemia, coronary disease, echocardiography, myocardial perfusion imaging

\section{CASE VIGNETTE}

A 60-year-old woman with stage 5 chronic kidney disease (CKD) from glomerulonephritis presented with atypical chest discomfort at rest. She is worried about coronary artery disease (CAD). She has hypertension treated with an angiotensin converting enzyme inhibitor and a beta blocker. Her total cholesterol is $5 \mathrm{mmol} / \mathrm{L}$ with low-density lipoprotein of $3.2 \mathrm{mmol} / \mathrm{L}$. She has no diabetes mellitus, no family history of premature $\mathrm{CAD}$, and does not smoke. How should she be evaluated?

\section{CLINICAL PROBLEM}

Cardiovascular disease (CVD) is the leading cause of mortality and a major cause of morbidity in the CKD population. Myocardial ischemia is a major cause of death in CKD patients. Myocardial ischemia can be caused by both epicardial and microvascular CAD.

Coronary artery disease is highly prevalent in the CKD population (1) being evident even in early renal disease $(2,3)$ and in young CKD patients (4). CKD patients have both traditional and non-traditional cardiac risk factors (Table $\mathbf{1}$ ).

In the CKD population, $\mathrm{CAD}$ is often multi-vessel and causes silent or asymptomatic myocardial ischemia $(5,6)$. Asymptomatic epicardial CAD has been detected even in people with early stage CKD (7) and is associated with a higher major adverse cardiac event rate compared to those without $\mathrm{CAD}$ (6). While the coronary plaque characteristics in patients with CKD showed no difference in the prevalence of high-risk plaque compared to the group without CKD (8), Kawai et al. showed that patients with mild CKD had higher prevalence of severe epicardial CAD compared to those without CKD (8), thus, suggesting that the problem relates to coronary stenosis rather than plaque stability.

Microvascular CAD is also present in the CKD population. Charytan et al. assessed mild to moderate CKD subjects without diabetes or uncontrolled hypertension using positron emission tomography imaging and found that the CKD cohort had decreased coronary flow reserve (CFR) compared to controls (9). Chade et al. suggested that microvascular dysfunction occurred in early CKD (10). They performed coronary flow wire to the left anterior descending artery using adenosine on early CKD subjects with no angiographically significant $\mathrm{CAD}$ and found the CKD subjects had lower CFR compared to normal controls (10). Microvascular CAD has been shown to be associated with reduced survival, although, similar to patients without CKD, the rate of survival is better than for epicardial CAD (11).

\section{STRATEGIES AND EVIDENCE DIAGNOSTIC EVALUATION}

Diagnostic evaluation starts with a thorough clinical history and examination and a baseline 12-lead ECG. Cardiovascular examination, especially to exclude uncontrolled hypertension or significant aortic stenosis is important prior to cardiac stress investigation. Cardiac stress investigations in CKD patients and their limitations are outlined in Table 2 .

\section{EXERCISE STRESS ECG}

In patients with normal renal function, exercise stress test (EST) with ECG has a low to moderate sensitivity and specificity, $68 \pm 16 \%$ and $77 \pm 17 \%$, respectively, even when adequate exercise capacity and $85 \%$ heart rate is achieved (12). EST is further limited in the advanced CKD population, with poor sensitivity of $36 \%$ (13) (especially those undergoing dialysis), as deconditioning leads to reduced exercise capacity (14). Deconditioning can be due to vascular, neurological or musculoskeletal comorbidities, and the catabolic/cachexic metabolic state associated with CKD. CKD patients have also been shown to have impaired heart rate response to exercise (15), and the frequently abnormal baseline ECG in CKD patients (often secondary to hypertension) hampers the interpretation of standard stress testing. In advanced CKD patients, the ST segment changes at stress were shown to be not 
significantly different between non-severe CAD and severe CAD group, despite a longer treadmill exercise time in the non-severe group (13).

\section{EXERCISE STRESS ECHOCARDIOGRAPHY AND DOBUTAMINE STRESS ECHOCARDIOGRAPHY}

Exercise stress echocardiography (ESE) is better than the standard stress ECG in ruling in CAD (Positive likelihood ratio ESE 7.94 versus EST 3.57) and ruling out CAD (Negative likelihood ratio ESE 0.19 versus EST 0.38) (16). Its sensitivity has been reported ranging from 71 to $97 \%$ with specificity ranging from 64 to $90 \%$ (17). However, the utility of ESE in CKD population remains limited due to the same physical reasons as EST limitations above.

The addition of echocardiography allows assessment of ventricular size and function, aortic and mitral valvular calcification, left ventricular hypertrophy (LVH), and potentially CFR. CFR measurement by Doppler echocardiography in the left anterior

\begin{tabular}{ll}
$\begin{array}{l}\text { Table } \mathbf{1} \text { | Cardiovascular risk factors in the chronic kidney disease } \\
\text { population. }\end{array}$ \\
\hline $\begin{array}{ll}\text { Traditional cardiovascular } \\
\text { risk factors }\end{array}$ & $\begin{array}{l}\text { Non-traditional cardiovascular } \\
\text { risk factors }\end{array}$ \\
\hline Hypertension & Left ventricular hypertrophy \\
Diabetes mellitus & Fluid overload \\
Dyslipidemia & Uremia \\
Smoking & Anemia \\
Family history of coronary artery & Disorders of vitamin D, calcium, and \\
disease & phosphate \\
Age & Hyperparathyroidism \\
& Inflammatory state \\
& Proteinuria \\
& Nephrotic state
\end{tabular}

descending artery has been shown to be a determinant of cardiac events in CKD patients in the absence of obstructive epicardial CAD (18), although this is not performed routinely by many echocardiography laboratories due to technical difficulties.

Dobutamine and dipyridamole stress echocardiography (DSE) technique detects inducible myocardial ischemia based on detection of wall motion abnormalities, thus, would detect significant epicardial CAD, not microvascular disease.

A meta analysis in 2008 showed that dipyridamole and dobutamine stress echocardiography had a sensitivity of $85 \%$ (confidence interval 80-89) and 86\% (confidence interval 78-91), respectively, and a specificity of $89 \%$ (confidence interval 82-94) and $86 \%$ (confidence interval 75-89), respectively, in detecting myocardial ischemia in the non-renal population (19). It is often recommended as a screening test in advanced CKD patients.

A systematic review in 2011 identified 11 DSE studies with 690 potential renal transplant recipients (19). Overall, DSE had moderate sensitivity of $80 \%$ (confidence interval 64-90) in detecting inducible myocardial ischemia in renal transplant candidates (20). Several mechanisms may explain the reduced accuracy of DSE in the advanced CKD population. The majority of advanced CKD patients had a blunted chronotropic response, thus, did not achieve $85 \%$ maximal predicted heart rate despite the use of atropine, significantly reducing the sensitivity of DSE in detecting myocardial ischemia (21). The thick myocardium due to LVH with small intracavitary volume, commonly found in CKD patients, obscures the detection of wall motion abnormalities at stress, thus, significantly reducing the sensitivity of stress echocardiography in detecting inducible myocardial ischemia in CKD population. Microvascular CAD is difficult to appreciate given the focus on regional wall motion abnormality and likely to be missed.

Abnormal DSE results in CKD patients have been associated with poorer prognosis for cardiac events and overall mortality (13, 22-24). Bergeron et al. showed that among 485 patients with CKD,

Table 2 | Cardiac stress investigations in the normal renal function versus advanced chronic kidney disease (CKD) patients

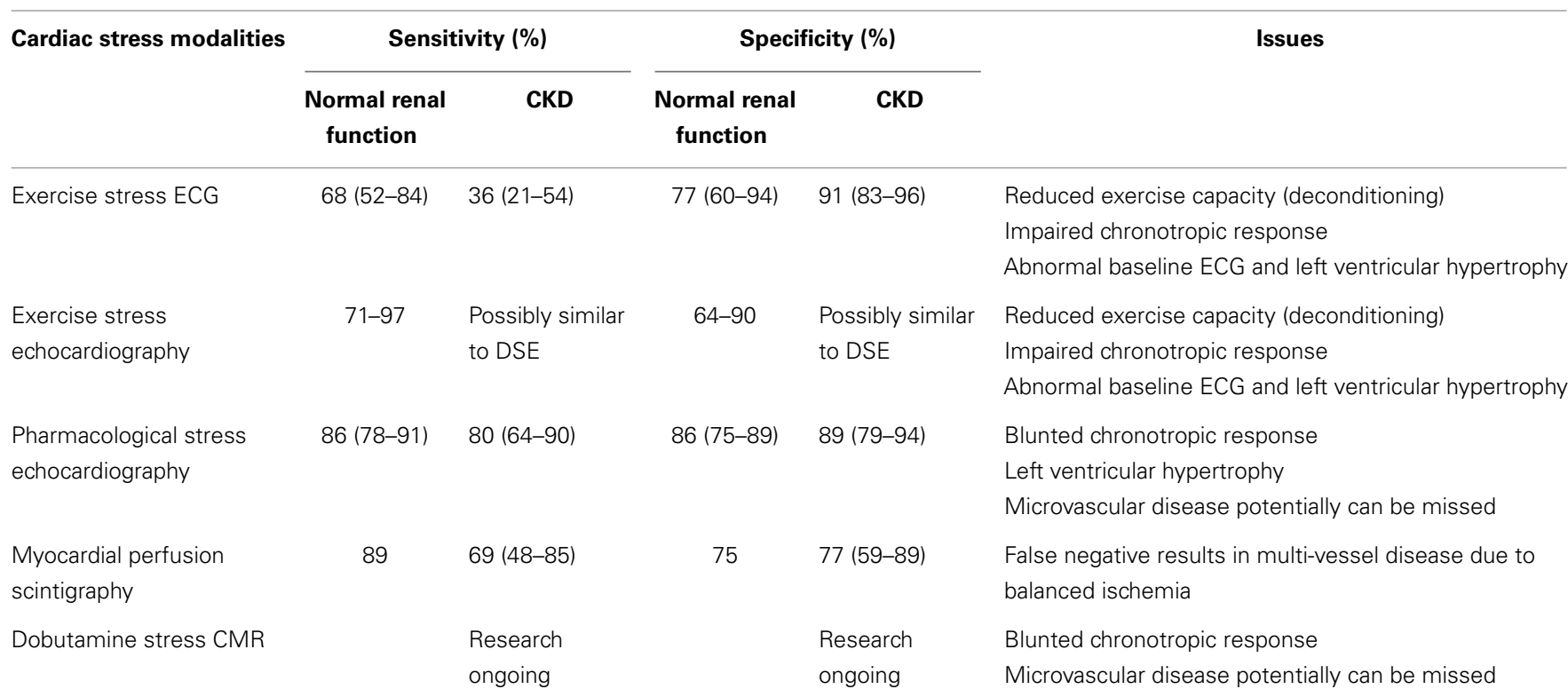


the percentage of ischemic segments during DSE was an independent predictor of mortality (22). Negative stress echocardiography results, on the other hand, have been shown to be associated with low incidence of major adverse cardiac events (21).

Blunted chronotropic response with exercise in CKD population may relate to poorer overall cardiac prognosis. A 2012 meta analysis of 11,542 patients showed that submaximal age-predicted heart rate ( $<85 \%$ maximum heart rate) in the setting of normal ESE and DSE had higher cardiovascular risk than those who achieved $>85 \%$ maximal predicted heart rate (25).

\section{MYOCARDIAL PERFUSION SCINTIGRAPHY}

Exercise and pharmacological myocardial perfusion scintigraphy (MPS) have sensitivity of 87 and $89 \%$, and specificity of 73 and $75 \%$, respectively, in detecting $>50 \%$ coronary artery stenosis in patients without advanced CKD (26). Exercise MPS in the advanced CKD population has the same limitation as EST and ESE, i.e., related to the inadequate exercise performance and chronotropic incompetence (27).

A systematic review in 2011 showed that MPS has sensitivity of $69 \%$ (confidence interval $48-85$ ) and specificity of $77 \%$ (confidence interval 59-89) in diagnosing inducible myocardial ischemia in the pre-renal transplant population (20). MPS has high false negative result in detecting ischemia in people with significant triple vessel CAD, as in the CKD population, because of homogeneous tracer uptake due to "balanced ischemia" $(28,29)$.

Normal myocardial perfusion measured by SPECT may not be associated with excellent prognosis in CKD population unlike the normal population $(30,31)$, perhaps due to the high-false negative result from balanced ischemia. Hakeem et al. showed patients with CKD with normal MPS still had a three times higher cardiac death rate than those with normal MPS and no CKD (31). In addition, concurrent reduced CFR and LVH may play a role. Fukushima et al. reported CKD patients with normal clinical myocardial perfusion by PET scan had reduced global myocardial flow reserve, which implied an underlying microvascular dysfunction in this population (32) that could explain the poorer prognosis. Increased baseline myocardial blood flow and peripheral endothelial dysfunction in CKD patients have been suggested by Koivuviita et al. (33).

Nonetheless, abnormal MPS results in CKD patients have been shown to be associated with a higher incidence of cardiac events and mortality (34-40). A meta analysis of 12 studies of prerenal transplant patients showed that the presence of reversible defects of inducible myocardial ischemia was associated with sixfold increased risk of myocardial infarction and almost fourfold risk of cardiac death (41). The presence of fixed defects was associated with a nearly fivefold increased risk of cardiac death (41). Joki et al. suggested that myocardial perfusion abnormalities significantly predicted cardiac events in CKD patients independently of eGFR and left ventricular ejection fraction (34). Among 2967 patients with $\mathrm{CKD}$, the incidence of major adverse cardiac events at 1 year was $1.0,3.9,5.9$, and $7.3 \%$ for normal, mild, moderate, and severe summed stress score, respectively (36). Al-Mallah et al. demonstrated that an interaction between renal function and the magnitude of perfusion deficit assessed by stress MPS in patients with moderate and severe CKD in the presence of abnormal MPS (38).
Blunted heart rate response in CKD patients during stress myocardial perfusion imaging has been reported to be associated with increased mortality (42-44).

\section{CARDIOVASCULAR MAGNETIC RESONANCE}

Cardiovascular magnetic resonance (CMR) with gadolinium contrast has not been widely utilized clinically in the CKD population due to the concern of nephrogenic systemic fibrosis (NSF) (4547). The use of Gadolinium chelates is prohibitive in CKD patients due to the rare but serious side effect of NSF. NSF manifests as a hardening of the skin and internal organs resembling scleroderma, which is irreversible and potentially fatal.

Cardiovascular magnetic resonance spectroscopy has been studied to assess early cardiac dysfunction in pediatric population with advanced CKD (48). Dobutamine stress CMR was shown to be safe in the pre-renal transplant population (49).

\section{RECOMMENDATION}

Exercise tolerance has utmost importance both for prognosis and symptoms capacity and has implication in the case of perioperative risk assessment (50), in this case, renal transplantation. Therefore, we recommend ESE to the case vignette described, to exclude inducible myocardial ischemia, inducible arrhythmia, and to assess exercise capacity and symptoms objectively. Resting echocardiography is useful to exclude significant aortic stenosis prior to exercise stress and to visually assess the degree of LVH.

\section{FUTURE DEVELOPIMENTS}

Further research is needed for better diagnostic testing for myocardial ischemia in CKD. A new non-contrast blood oxygen level dependent (BOLD) CMR technique has been utilized in several human studies to assess myocardial oxygenation as a measure of ischemia with promising benefits (51-57), namely, in syndrome $\mathrm{X}$, hypertensive patients, patients with $\mathrm{CAD}$, hypertrophic cardiomyopathy, and aortic stenosis. It detects both epicardial and microvascular CAD without the use of potentially toxic Gadolinium chelate contrast agents. The combination of non-contrast BOLD CMR and non-contrast whole-heart magnetic resonance coronary angiography, which can characterize significant proximal epicardial CAD, has potential for assessing myocardial ischemia in the advanced CKD population. This needs to be tested in prospective studies.

\section{REFERENCES}

1. Stack AG, Bloembergen WE. Prevalence and clinical correlates of coronary artery disease among new dialysis patients in the United States: a cross-sectional study. J Am Soc Nephrol (2001) 12(7):1516-23.

2. Joosen IA, Schiphof F, Versteylen MO, Laufer EM, Winkens MH, Nelemans PJ, et al. Relation between mild to moderate chronic kidney disease and coronary artery disease determined with coronary CT angiography. PLoS One (2012) 7(10):e47267. doi:10.1371/journal.pone.0047267

3. Henry RM, Kostense PJ, Bos G, Dekker JM, Nijpels G, Heine RJ, et al. Mild renal insufficiency is associated with increased cardiovascular mortality: the Hoorn Study. Kidney Int (2002) 62(4):1402-7. doi:10.1111/j.1523-1755.2002.kid571.x

4. Goodman WG, Goldin J, Kuizon BD, Yoon C, Gales B, Sider D, et al. Coronaryartery calcification in young adults with end-stage renal disease who are undergoing dialysis. N Engl J Med (2000) 342(20):1478-83. doi:10.1056/ NEJM200005183422003

5. Ohtake T, Kobayashi S, Moriya H, Negishi K, Okamoto K, Maesato K, et al. High prevalence of occult coronary artery stenosis in patients with chronic kidney 
disease at the initiation of renal replacement therapy: an angiographic examination. J Am Soc Nephrol (2005) 16(4):1141-8. doi:10.1681/ASN.2004090765

6. Hase $\mathrm{H}$, Tsunoda T, Tanaka $\mathrm{Y}$, Takahashi $\mathrm{Y}$, Imamura $\mathrm{Y}$, Ishikawa $\mathrm{H}$, et al. Risk factors for de novo acute cardiac events in patients initiating hemodialysis with no previous cardiac symptom. Kidney Int (2006) 70(6):1142-8. doi:10.1038/sj.ki.5001726

7. Cho I, Min HS, Chun EJ, Park SK, Choi Y, Blumenthal RS, et al. Coronary atherosclerosis detected by coronary $\mathrm{CT}$ angiography in asymptomatic subjects with early chronic kidney disease. Atherosclerosis (2010) 208(2):406-11. doi:10.1016/j.atherosclerosis.2009.08.040

8. Kawai H, Sarai M, Motoyama S, Harigaya H, Ito H, Sanda Y, et al. Coronary plaque characteristics in patients with mild chronic kidney disease. Analysis by 320-row area detector computed tomography. Circ J (2012) 76(6):1436-41. doi:10.1253/circj.CJ-11-1384

9. Charytan DM, Shelbert HR, Di Carli MF. Coronary microvascular function in early chronic kidney disease. Circ Cardiovasc Imaging (2010) 3(6):663-71. doi:10.1161/CIRCIMAGING.110.957761

10. Chade AR, Brosh D, Higano ST, Lennon RJ, Lerman LO, Lerman A. Mild renal insufficiency is associated with reduced coronary flow in patients with non-obstructive coronary artery disease. Kidney Int (2006) 69(2):266-71. doi:10.1038/sj.ki.5000031

11. Lin T, Rechenmacher S, Rasool S, Varadarajan P, Pai RG. Reduced survival in patients with "coronary microvascular disease". Int J Angiol (2012) 21(2):89-94. doi:10.1055/s-0032-1315799

12. Gianrossi R, Detrano R, Mulvihill D, Lehmann K, Dubach P, Colombo A, et al. Exercise-induced ST depression in the diagnosis of coronary artery disease. A meta-analysis. Circulation (1989) 80(1):87-98. doi:10.1161/01.CIR.80.1.87

13. Sharma R, Pellerin D, Gaze DC, Gregson H, Streather CP, Collinson PO, et al. Dobutamine stress echocardiography and the resting but not exercise electrocardiograph predict severe coronary artery disease in renal transplant candidates. Nephrol Dial Transplant (2005) 20(10):2207-14. doi:10.1093/ndt/ gfio05

14. Schmidt A, Stefenelli T, Schuster E, Mayer G. Informational contribution of noninvasive screening tests for coronary artery disease in patients on chronic renal replacement therapy. Am J Kidney Dis (2001) 37(1):56-63. doi:10.1053/ ajkd.2001.20584

15. Howden EJ, Weston K, Leano R, Sharman JE, Marwick TH, Isbel NM, et al. Cardiorespiratory fitness and cardiovascular burden in chronic kidney disease. J Sci Med Sport (2014). doi:10.1016/j.jsams.2014.07.005

16. Banerjee A, Newman DR, Van den Bruel A, Heneghan C. Diagnostic accuracy of exercise stress testing for coronary artery disease: a systematic review and meta-analysis of prospective studies. Int J Clin Pract (2012) 66(5):477-92. doi:10.1111/j.1742-1241.2012.02900.x

17. Armstrong WF, Zoghbi WA. Stress echocardiography: current methodology and clinical applications. J Am Coll Cardiol (2005) 45(11):1739-47. doi:10.1016/j. jacc.2004.12.078

18. Nakanishi K, Fukuda S, Shimada K, Miyazaki C, Otsuka K, Kawarabayashi T, et al. Prognostic value of coronary flow reserve on long-term cardiovascular outcomes in patients with chronic kidney disease. Am J Cardiol (2013) 112(7):928-32. doi:10.1016/j.amjcard.2013.05.025

19. Picano E, Molinaro S, Pasanisi E. The diagnostic accuracy of pharmacological stress echocardiography for the assessment of coronary artery disease: a metaanalysis. Cardiovasc Ultrasound (2008) 6:30. doi:10.1186/1476-7120-6-30

20. Wang LW, Fahim MA, Hayen A, Mitchell RL, Lord SW, Baines LA, et al. Cardiac testing for coronary artery disease in potential kidney transplant recipients: a systematic review of test accuracy studies. Am J Kidney Dis (2011) 57(3):476-87. doi:10.1053/j.ajkd.2010.11.018

21. Tita C, Karthikeyan V, Stroe A, Jacobsen G, Ananthasubramaniam K. Stress echocardiography for risk stratification in patients with end-stage renal disease undergoing renal transplantation. J Am Soc Echocardiogr (2008) 21(4):321-6. doi:10.1016/j.echo.2007.06.004

22. Bergeron S, Hillis GS, Haugen EN, Oh JK, Bailey KR, Pellikka PA. Prognostic value of dobutamine stress echocardiography in patients with chronic kidney disease. Am Heart J (2007) 153(3):385-91. doi:10.1016/j.ahj.2006.11.012

23. Herzog CA, Marwick TH, Pheley AM, White CW, Rao VK, Dick CD. Dobutamine stress echocardiography for the detection of significant coronary artery disease in renal transplant candidates. Am J Kidney Dis (1999) 33(6):1080-90. doi:10.1016/S0272-6386(99)70145-9
24. Marwick TH, Lauer MS, Lobo A, Nally J, Braun W. Use of dobutamine echocardiography for cardiac risk stratification of patients with chronic renal failure. J Intern Med (1998) 244(2):155-61. doi:10.1046/j.1365-2796.1998.00354.x

25. Makani H, Bangalore S, Halpern D, Makwana HG, Chaudhry FA. Cardiac outcomes with submaximal normal stress echocardiography: a meta-analysis. J Am Coll Cardiol (2012) 60(15):1393-401. doi:10.1016/j.jacc.2012.05.041

26. Salerno M, Beller GA. Noninvasive assessment of myocardial perfusion. Circ Cardiovasc Imaging (2009) 2(5):412-24. doi:10.1161/CIRCIMAGING.109. 854893

27. De Vriese AS, Vandecasteele SJ, Van den Bergh B, De Geeter FW. Should we screen for coronary artery disease in asymptomatic chronic dialysis patients? Kidney Int (2012) 81(2):143-51. doi:10.1038/ki.2011.340

28. Bourque JM, Beller GA. Stress myocardial perfusion imaging for assessing prognosis: an update. JACC Cardiovasc Imaging (2011) 4(12):1305-19. doi:10.1016/j.jcmg.2011.10.003

29. Lima RS, Watson DD, Goode AR, Siadaty MS, Ragosta M, Beller GA, et al. Incremental value of combined perfusion and function over perfusion alone by gated SPECT myocardial perfusion imaging for detection of severe three-vessel coronary artery disease. J Am Coll Cardiol (2003) 42(1):64-70. doi:10.1016/S07351097(03)00562-X

30. Furuhashi T, Moroi M, Joki N, Hase H, Minakawa M, Masai H, et al. Prediction of cardiovascular events in pre-dialysis chronic kidney disease patients with normal SPECT myocardial perfusion imaging. J Cardiol (2014) 63(2):154-8. doi:10.1016/j.jjcc.2013.07.011

31. Hakeem A, Bhatti S, Dillie KS, Cook JR, Samad Z, Roth-Cline MD, et al. Predictive value of myocardial perfusion single-photon emission computed tomography and the impact of renal function on cardiac death. Circulation (2008) 118(24):2540-9. doi:10.1161/CIRCULATIONAHA.108.788109

32. Fukushima K, Javadi MS, Higuchi T, Bravo PE, Chien D, Lautamaki R, et al. Impaired global myocardial flow dynamics despite normal left ventricular function and regional perfusion in chronic kidney disease: a quantitative analysis of clinical 82Rb PET/CT studies. J Nucl Med (2012) 53(6):887-93. doi:10.2967/jnumed.111.099325

33. Koivuviita N, Tertti R, Jarvisalo M, Pietila M, Hannukainen J, Sundell J, et al. Increased basal myocardial perfusion in patients with chronic kidney disease without symptomatic coronary artery disease. Nephrol Dial Transplant (2009) 24(9):2773-9. doi:10.1093/ndt/gfp175

34. Joki N, Hase H, Kawano Y, Nakamura S, Nakajima K, Hatta T, et al. Myocardial perfusion imaging for predicting cardiac events in Japanese patients with advanced chronic kidney disease: 1-year interim report of the J-ACCESS 3 investigation. Eur J Nucl Med Mol Imaging (2014) 41(9):1701-9. doi:10.1007/s00259014-2781-z

35. Bhatti S, Hakeem A, Dhanalakota S, Palani G, Husain Z, Jacobsen G, et al. Prognostic value of regadenoson myocardial single-photon emission computed tomography in patients with different degrees of renal dysfunction. Eur Heart J Cardiovasc Imaging (2014) 15(8):933-40. doi:10.1093/ehjci/jeu036

36. Yoda S, Nakanishi K, Tano A, Kasamaki Y, Kunimoto S, Matsumoto N, et al. Risk stratification of cardiovascular events in patients at all stages of chronic kidney disease using myocardial perfusion SPECT. J Cardiol (2012) 60(5):377-82. doi:10.1016/j.jjcc.2012.06.011

37. Okuyama C, Nakajima K, Hatta T, Nishimura S, Kusuoka H, Yamashina $\mathrm{A}$, et al. Incremental prognostic value of myocardial perfusion single photon emission computed tomography for patients with diabetes and chronic kidney disease. Nucl Med Commun (2011) 32(10):913-9. doi:10.1097/MNM. 0b013e3283495787

38. Al-Mallah MH, Hachamovitch R, Dorbala S, Di Carli MF. Incremental prognostic value of myocardial perfusion imaging in patients referred to stress singlephoton emission computed tomography with renal dysfunction. Circ Cardiovasc Imaging (2009) 2(6):429-36. doi:10.1161/CIRCIMAGING.108.831164

39. Hatta T, Nishimura S, Nishimura T. Prognostic risk stratification of myocardial ischaemia evaluated by gated myocardial perfusion SPECT in patients with chronic kidney disease. Eur J Nucl Med Mol Imaging (2009) 36(11):1835-41. doi:10.1007/s00259-009-1165-2

40. Momose M, Babazono T, Kondo C, Kobayashi H, Nakajima T, Kusakabe K. Prognostic significance of stress myocardial ECG-gated perfusion imaging in asymptomatic patients with diabetic chronic kidney disease on initiation of haemodialysis. Eur J Nucl Med Mol Imaging (2009) 36(8):1315-21. doi:10.1007/s00259-009-1110-4 
41. Rabbat CG, Treleaven DJ, Russell JD, Ludwin D, Cook DJ. Prognostic value of myocardial perfusion studies in patients with end-stage renal disease assessed for kidney or kidney-pancreas transplantation: a meta-analysis. J Am Soc Nephrol (2003) 14(2):431-9. doi:10.1097/01.ASN.0000047560.51444.3A

42. Hage FG, Dean P, Bhatia V, Iqbal F, Heo J, Iskandrian AE. The prognostic value of the heart rate response to adenosine in relation to diabetes mellitus and chronic kidney disease. Am Heart J (2011) 162(2):356-62. doi:10.1016/j.ahj.2011.05.014

43. Hage FG, Dean P, Iqbal F, Heo J, Iskandrian AE. A blunted heart rate response to regadenoson is an independent prognostic indicator in patients undergoing myocardial perfusion imaging. J Nucl Cardiol (2011) 18(6):1086-94. doi:10.1007/s12350-011-9429-1

44. Venkataraman R, Hage FG, Dorfman TA, Heo J, Aqel RA, de Mattos AM, et al. Relation between heart rate response to adenosine and mortality in patients with end-stage renal disease. Am J Cardiol (2009) 103(8):1159-64. doi:10.1016/j.amjcard.2009.01.007

45. Saxena SK, Sharma M, Patel M, Oreopoulos D. Nephrogenic systemic fibrosis: an emerging entity. Int Urol Nephrol (2008) 40(3):715-24. doi:10.1007/s11255008-9361-8

46. Rydahl C, Thomsen HS, Marckmann P. High prevalence of nephrogenic systemic fibrosis in chronic renal failure patients exposed to gadodiamide, a gadoliniumcontaining magnetic resonance contrast agent. Invest Radiol (2008) 43(2):141-4. doi:10.1097/RLI.0b013e31815a3407

47. Othersen JB, Maize JC, Woolson RF, Budisavljevic MN. Nephrogenic systemic fibrosis after exposure to gadolinium in patients with renal failure. Nephrol Dial Transplant (2007) 22(11):3179-85. doi:10.1093/ndt/gfm584

48. Malatesta-Muncher R, Wansapura J, Taylor M, Lindquist D, Hor K, Mitsnefes M. Early cardiac dysfunction in pediatric patients on maintenance dialysis and post kidney transplant. Pediatr Nephrol (2012) 27(7):1157-64. doi:10.1007/s00467-012-2124-x

49. Ripley DP, Kannoly S, Gosling OE, Hossain E, Chawner RR, Moore J, et al. Safety and feasibility of dobutamine stress cardiac magnetic resonance for cardiovascular assessment prior to renal transplantation. J Cardiovasc Med (Hagerstown) (2014) 15(4):288-94.

50. Fleisher LA, Beckman JA, Brown KA, Calkins H, Chaikof EL, Fleischmann KE, et al. ACC/AHA 2007 guidelines on perioperative cardiovascular evaluation and care for noncardiac surgery: executive summary: a report of the American College of Cardiology/American Heart Association Task Force on Practice Guidelines (Writing Committee to Revise the 2002 Guidelines on Perioperative Cardiovascular Evaluation for Noncardiac Surgery) developed in collaboration with the American Society of Echocardiography, American Society of Nuclear Cardiology, Heart Rhythm Society, Society of Cardiovascular Anesthesiologists, Society for Cardiovascular Angiography and Interventions, Society for Vascular Medicine and Biology, and Society for Vascular Surgery. J Am Coll Cardiol (2007) 50(17):1707-32.

51. Karamitsos TD, Arnold JR, Pegg TJ, Francis JM, Birks J, Jerosch-Herold M, et al. Patients with syndrome $\mathrm{X}$ have normal transmural myocardial perfusion and oxygenation: a 3-T cardiovascular magnetic resonance imaging study. Circ Cardiovasc Imaging (2012) 5(2):194-200. doi:10.1161/CIRCIMAGING.111.969667

52. Karamitsos TD, Leccisotti L, Arnold JR, Recio-Mayoral A, Bhamra-Ariza P, Howells RK, et al. Relationship between regional myocardial oxygenation and perfusion in patients with coronary artery disease: insights from cardiovascular magnetic resonance and positron emission tomography. Circ Cardiovasc Imaging (2010) 3(1):32-40. doi:10.1161/CIRCIMAGING.109.860148

53. Wacker CM, Hartlep AW, Pfleger S, Schad LR, Ertl G, Bauer WR. Susceptibilitysensitive magnetic resonance imaging detects human myocardium supplied by a stenotic coronary artery without a contrast agent. J Am Coll Cardiol (2003) 41(5):834-40. doi:10.1016/S0735-1097(02)02931-5

54. Friedrich MG, Niendorf T, Schulz-Menger J, Gross CM, Dietz R. Blood oxygen level-dependent magnetic resonance imaging in patients with stress-induced angina. Circulation (2003) 108(18):2219-23. doi:10.1161/01.CIR.0000095271. 08248.EA

55. Beache GM, Herzka DA, Boxerman JL, Post WS, Gupta SN, Faranesh AZ, et al. Attenuated myocardial vasodilator response in patients with hypertensive hypertrophy revealed by oxygenation-dependent magnetic resonance imaging. Circulation (2001) 104(11):1214-7. doi:10.1161/hc3601.096307

56. Karamitsos TD, Dass S, Suttie J, Sever E, Birks J, Holloway CJ, et al. Blunted myocardial oxygenation response during vasodilator stress in patients with hypertrophic cardiomyopathy. J Am Coll Cardiol (2013) 61(11):1169-76. doi: 10.1016/j.jacc.2012.12.024

57. Mahmod M, Francis JM, Pal N, Lewis A, Dass S, De Silva R, et al. Myocardial perfusion and oxygenation are impaired during stress in severe aortic stenosis and correlate with impaired energetics and subclinical left ventricular dysfunction. J Cardiovasc Magn Reson (2014) 16:29. doi:10.1186/1532-429X-16-29

Conflict of Interest Statement: The authors declare that the research was conducted in the absence of any commercial or financial relationships that could be construed as a potential conflict of interest.

Received: 02 November 2014; paper pending published: 18 November 2014; accepted: 07 December 2014; published online: 19 December 2014.

Citation: Parnham SFC, Gleadle JM, De Pasquale CG and Selvanayagam JB (2014) Myocardial ischemia assessment in chronic kidney disease: challenges and pitfalls. Front. Cardiovasc. Med. 1:13. doi: 10.3389/fcvm.2014.00013

This article was submitted to Cardiovascular Imaging, a section of the journal Frontiers in Cardiovascular Medicine.

Copyright $\odot 2014$ Parnham, Gleadle, De Pasquale and Selvanayagam. This is an openaccess article distributed under the terms of the Creative Commons Attribution License (CC BY). The use, distribution or reproduction in other forums is permitted, provided the original author(s) or licensor are credited and that the original publication in this journal is cited, in accordance with accepted academic practice. No use, distribution or reproduction is permitted which does not comply with these terms. 